\title{
FENOMENOLOGIA E PSICOLOGIA: DIÁLOGOS E INTERLOCUÇÕES ${ }^{1}$
}

\author{
Phenomenology and Psychology: Dialogues and Discourses
}

Fenomenología y Psicología: Dialogos y Interlocuciones

Adriano Holanda

\begin{abstract}
Resumo: O artigo propõe uma discussão em torno das relações entre Psicologia e Fenomenologia, tomando as duas disciplinas a partir de uma proximidade conceitual e formal. Principia por definir a Fenomenologia como uma epistemologia, um método, uma filosofia e uma ciência. O desenvolvimento do texto se apóia em quatro pontos, apresentados como pro-vocações, a saber: a) Que toda psicologia é e deve ser fenomenológica; b) Que a fenomenologia, em sua radicalidade, desemboca - necessariamente, numa ética da intersubjetividade e numa filosofia da existência; c) Que o pensamento fenomenológico no Brasil se constrói por vias diversas da filosofia husserliana, fazendo com que esta venha a ser conhecida tardiamente, o que provoca um "atraso" nos debates com a Fenomenologia em nosso país, e; d) Que Husserl pode ser considerado um psicólogo. Pretende-se apontar para o fato que os entrelaçamentos entre Fenomenologia e Psicologia são mais estreitos do que a literatura tradicional aponta.

Palavras-chave: Fenomenologia; Psicologia; Husserl; História da Psicologia no Brasil.
\end{abstract}

Abstract: This article proposes a discussion about the relations between Psychology and Phenomenology, taking both disciplines, from his formal and conceptual proximity. It begins by defining phenomenology like an epistemology, a method, a philosophy and a science. The article is developed in four points, presented like pro-vocations: a) That all psychology is and must be phenomenological; b) That's phenomenology, in his radical way, it will be - necessarily - an ethics of intersubjectivity and a philosophy of existence; c) That the phenomenological thinking, in Brazil, was built by other ways that the husserlian philosophy, and that causes misunderstandings in discussions about phenomenology in Brazil, and; d) That Husserl may be considered a psychologist. The article pretends to point that the connections between Psychology and Phenomenology are more close than pointed by traditional literature.

Keywords: Phenomenology; Psychology; Husserl; History of Psychology in Brazil.

Resumen: El artículo se propone una discusión alrededor de las relaciones entre Fenomenología y Psicología, tomando las dos disciplinas a partir de una proximidad conceptual y formal. Empieza la discusión por la definición de la Fenomenología como una epistemología, un método, una filosofía y una ciencia. Hace el desarrollo del texto apoyado en cuatro puntos, presentados acá como pro-vocaciones: a) Que toda psicología es y debe ser fenomenológica; b) Que la fenomenología, en su radicalidad, se torna - necesariamente - una ética de la intersubjetividad y una filosofía de la existencia; c) Que lo pensamiento fenomenológico en Brasil, se constituye por caminos diversos de la filosofía de Husserl, haciendo con que esta ultima solo venga a ser conocida de manera tardía, lo que provoca un "atraso" en los debates cerca de la Fenomenología en el país, e; d) Que Husserl puede ser considerado un psicólogo. Se pretende apuntar que los enredos entre Fenomenología y Psicología son más cercanos que lo que la literatura tradicional apunta.

Palabras-clave: Fenomenologia; Psicología; Husserl; History de la Psicología en Brasil.

"Sem evidência, não há ciência" (Edmund Husserl)

\section{Introdução}

Em Física Fenomenológica, seu autor - Raimundo Alberto Normando (1985) - apresenta “a física trabalhá-

Palestra proferida na mesa de encerramento do I Congresso Sul-Brasileiro de Fenomenologia \& I Congresso de Estudos Fenomenológicos do Paraná, realizado na Universidade Federal do Paraná (UFPR), em Curitiba, de 04 a 07 de junho de 2009. vel” ou, em suas próprias palavras, "a Física funcionando". Voltaremos a isto.

Temos apresentado a Fenomenologia em nossos cursos - para psicólogos e estudantes - a partir de um tripé compreensivo, a saber: a) a fenomenologia deve ser preliminarmente entendida como uma epistemologia, dado que decorre da questão da fundamentação do conhecimento e do como se dá o "conhecer”, a grande motivação para sua construção; b) a fenomenologia é um método, e como tal nos permite o acesso livre ao mundo, aos fenômenos e à própria constituição desse sujeito que acessa $\mathrm{e}$ interage com o mundo; e, c) a fenomenologia é igualmente, mas apenas como conseqüência, e não como premissa 
básica, uma filosofia, que na sua radicalidade reconhece o homem, fundando-se e fundando diversas outras perspectivas, sejam estas antropológicas, sociológicas, psicológicas, etc.

Todavia, é necessário reafirmarmos outra posição decorrente das demais, a nosso ver - mas não suficientemente clarificada pelas diversas leituras (muitas vezes apressadas e simplificadoras) desse autor por demais rigoroso, "pesado" e difícil que é Husserl, o que justifica em grande medida as incompreensões e interpretações enviesadas de seu pensamento: trata-se do fato que a fenomenologia é, igualmente, uma ciência, na sua acepção mais tácita, ou seja, como "conhecimento atento e aprofundado de alguma coisa”, ou como "noção precisa”, como conhecimento sistematizado a respeito de algo. Esta é uma singular característica do pensamento husserliano evitada inadvertidamente por boa parte das interpretações psicológicas, sejam estas modernas ou não.

Isto explica, em parte, como são sedutoras as filosofias da existência alicerçadas na fenomenologia, e o quanto que - curiosamente - opõem-se estas ao método husserliano. Espero poder afirmar aqui a consideração de Husserl como um "filósofo da existência”, tanto quanto o foram Kierkegaard, Nietzsche, Sartre, Merleau-Ponty ou Heidegger, visto que, à exceção dos dois primeiros, os demais construíram seus pensamentos em continuidade ao de Husserl. Mas deixemos esta afirmativa para adiante.

Agora, retornando à nossa primeira frase - sobre a física - tomemos a Fenomenologia como um pensamento em ato; façamos à fenomenologia "funcionar", e veremos simplesmente a realidade se desvelando ao nosso redor.

Uma última palavra sobre a questão da ciência. Retomando palavras de um dos mais ardorosos defensores do saber científico da modernidade, o astrônomo Carl Sagan, a ciência é o mais democrático dos movimentos humanos, pois não sobrevive ao erro e está sempre se atualizando.

\section{Um Primeiro Ponto}

Tem-se falado continuadamente em um sem número de caminhos para a fenomenologia, que se intercalam e se entrecruzam, se completam e abrem novas perspectivas. Mas falar do diálogo e das interlocuções entre Psicologia e Fenomenologia me parece ser um retorno à própria perspectiva histórica, tanto de uma, quanto de outra. Ocorre que o "lugar" da psicologia no seio da fenomenologia está devidamente guardado, mas o "lugar" da fenomenologia na psicologia ainda está para ser definido e, podemos dizer, está sendo ainda construído.

Com base nesta perspectiva, é que arriscamos uma primeira afirmação: toda psicologia é e deve ser fenomenológica. Evidente, todavia, a necessidade de explicitarmos esta pro-vocação.
Husserl, em suas obras, bem apontou para a Fenomenologia como a clarificação do sentido íntimo das coisas, para a necessidade de tomarmos os fenômenos “em pessoa". Buscava com isto, uma base sólida para a Filosofia, de tal forma que a sustentasse tal qual uma ciência rigorosa. E, essa base sólida, a encontra nas "evidências apodíticas”, indubitáveis, que não podem ser refutadas, indiscutíveis. Desnecessário, aqui, assinalar o claro débito e vínculo com a filosofia cartesiana. Mas, necessário sim, reafirmar o fato que a Fenomenologia deve ser entendida como uma ciência - de molde distinto do modelo naturalista, seguramente -, mas como uma ciência positiva, como afirma o próprio Husserl em suas Ideen (Husserl, 1985).

Esta prática científica, proposta por Husserl, caracteriza-se por ser uma "metodologia compreensiva", orientada para a descoberta e integrativa; portanto, não dissociativa. E tudo decorre da noção de intencionalidade. Presente na expressão "actus mentis quo tendit in objectum", correspondente ao que os escolásticos - retomados por Brentano - caracterizavam por ser a "in-existência intencional", ou seja, a "existência-em"2. É a direção espontânea da consciência para algo, como assinala Nilton Campos (1945).

Na construção do pensamento de Husserl, destaca-se o fato que o fenômeno subjetivo é, antes de tudo, intersubjetivo, ou que o mundo não é mais a minha representação, mas é o nosso mundo ou um intermundo, como coloca Merleau-Ponty.

Retornando às "evidências apodíticas", nos perguntamos se é possível uma psicologia que não esteja alicerçada nestas premissas. Será possível uma psicologia baseada em doxa, em opinião? Ou não será necessário colocarmos esta psicologia solidamente posicionada numa episteme? Conhecer - para a fenomenologia - é conhecer de maneira originária, o que inaugura uma nova "atitude" diante dos fenômenos: fenomenologia como evidenciação ou clarificação dos fenômenos, através da redução como o resgate (ou a recuperação) das coisas como são, de fato. Nas palavras de Husserl:

Antes de tudo o mais, é óbvia a existência do mundo - de tal modo que ninguém pode pensar em enunciá-la expressamente numa proposição. É que temos a experiência contínua do mundo, na qual este está sempre e inquestionavelmente diante dos olhos (Husserl, 1992, p. 13).

Neste sentido, não mais falamos em "revelar" o mundo, oculto de algum modo, mas em des-velar sentidos, naquilo que o mundo se apresenta para uma consciência, não mais como "coisa", mas como fenômeno e, portanto, como dotado de um conjunto de significados que incluem - de modo inalienável - todos os elementos da equação: sujeito, ato e mundo de fenômenos.

\footnotetext{
2 Do termo escolástico "innesse" ou "existência-dentro-de", segundo Brentano (Maciel, 2003).
} 
Voltando à psicologia: o que é um "fenômeno psicológico"? O que é o "querer”, o "penso", o "sentir”, o "desejo"? Temos, na psicologia, uma série de conceitos ou noções, usuais nas diversas práticas psicológicas sejam estas clínicas ou não - que são utilizadas continuadamente como definidoras dessas mesmas práticas, e que beiram as inferências metafísicas ou as alienações fantasiosas (bem próximas da noção platônica do "mundo das idéias", como algo inacessíveis e longínquas). Afinal de contas, o que é "relação" ou "contato", o que é "diálogo" ou "vínculo", "tele” ou mesmo "atitude", apenas para tomarmos o exemplo de algumas clínicas conhecidas?

Será possível fazermos uma psicologia sem uma "definição operacional” desses conceitos ou noções? Será possível construirmos uma psicologia sem uma fenomenologia desse vivido? O que pretendemos problematizar, e que justifica nossa tese, é que é necessária uma fenomenologia para a construção de uma psicologia, sob pena de construirmos outra coisa que não uma psicologia autônoma: talvez uma fisiologia psicológica ou uma sociologia psicológica, ou ainda uma antropologia psicológica ou mesmo uma física psicológica, mas não uma psicologia independente.

Entendemos aqui a possibilidade de uma "psicologia fenomenológica" como aquela que brota, que principia, da descrição da experiência empírica psicológica.

Um dos problemas mais centrais na questão da relação da Fenomenologia com as "teorias psicológicas” é o simples fato que não conhecemos fenomenologia, mas nos apropriamos dela em algumas idéias que são práticas ou úteis para justificarmos esta ou aquela concepção. A esta atitude designamos por apropriação indébita de conhecimento alheio.

Conhecer, saber, não é simplesmente dizer algo a respeito de, mas é compreender, é co-apreender, é terjunto, numa caminhada de descoberta, de "abertura”. Só assim podemos, por exemplo, considerar o inconsciente não mais como o lugar do não-sabido, mas o já-sabido no encobrimento.

\section{Um Segundo Ponto}

Gostaríamos, agora, de destacar um segundo ponto. Emanuel Lévinas (1989), em sua introdução ao Théorie de l'Intuition dans la Phénoménologie de Husserl já aponta para o fato que o método fenomenológico se trata de uma "maneira de filosofar" ou uma "atitude" diante do mundo como temos sucessivamente destacado em nossos debates.

Disto decorre nossa segunda afirmativa, igualmente forte, e que diz respeito ao caráter intrínseco do método fenomenológico. O método fenomenológico, levado à sua radicalidade, se torna - inevitavelmente - uma ética da intersubjetividade e uma filosofia da existência.
Novamente, recorremos a Lévinas como apoio e testemunho. Escreve ele:

Ao nos propormos a estudar aqui o intuitivismo na fenomenologia de Husserl, não podemos separar, por conseqüência, em nossa exposição, a teoria da intuição, como método filosófico, do que poderíamos chamar a ontologia de Husserl. Nós queremos, ao contrário, mostrar como a intuição que ele propõe como modo de filosofar, decorre de sua concepção de ser (Lévinas, 1989, p. 13).

Acrescentamos a esta citação, outra - mais conhecida, talvez - de Merleau-Ponty, em sua Phénoménologie de la Perception:

Mas todo Sein und Zeit saiu de uma indicação de Husserl e nada mais é do que uma explicitação do "Naturlichen Weltbegriff" ou do "Lebenswelt" que Husserl, no fim de sua vida, dava como tema principal da fenomenologia (Merleau-Ponty, 1945, p. I).

Associado a esta idéia - e como imediata conseqüência desta radicalização - temos ainda a condição necessariamente ética do pensamento fenomenológico, pautado pela consideração da intersubjetividade e pela colocação da consciência como doadora de sentido, o que desemboca na perspectiva de um sujeito em relação com o mundo.

Longe de ser, como se acreditou, a fórmula de uma filosofia idealista, a redução fenomenológica é a fórmula de uma filosofia existencialista: o "In-derWelt-Sein" ${ }^{3}$ de Heidegger somente aparece sobre o fundo da redução fenomenológica" (Merleau-Ponty, 1945, p. IX).

Inspirado na fenomenologia husserliana, MerleauPonty assinala que a redução fenomenológica evidencia a existência, o "ser no mundo" ou o "ser em situação", reiterando que nem o sujeito aparece como puro sujeito, nem o mundo como puro objeto, dado que "sou um campo, sou uma experiência” (Merleau-Ponty, 1945, p. 465).

\section{Um Terceiro Ponto}

Quero agora fazer um parêntese e tecer uma breve reflexão sobre a história da fenomenologia no Brasil, na expectativa de compreender o seguinte: Porque estamos apenas hoje discutindo Fenomenologia no Brasil? Porque este importante pensamento ainda não é de conhecimento público na maioria das academias?

A realidade atual da diversidade e da "confusão" entre modos de se pensar ou fazer fenomenologia se explica, a

O "ser-no-mundo". 
meu ver, pelo modo como se deu a entrada e a penetração do pensamento fenomenológico no país. Este breve parêntese tem por função apenas resgatar alguns dados históricos. Diríamos que a fenomenologia no Brasil tem dois "momentos": um precursor e outro fundador.

Nesta perspectiva, o grande precursor do pensamento fenomenológico no Brasil foi Raymundo de Farias Brito (1862-1917), considerado por muitos como um dos maiores filósofos de nossa história, é nascido na cidade de São Benedito, no sertão do Ceará e que fez seus primeiros estudos em Sobral. Formou-se em Direito em Recife, onde recebeu a influência de Tobias Barreto. Após formar-se trabalha em Belém e Fortaleza, findando sua carreira como catedrático de Lógica no Colégio Pedro II.

Foi Farias Brito quem assentou as bases do pensamento existencialista no Brasil, recebendo influências de Bergson, Fichte e da Escola de Würzburg (Penna, 1992; Gomes, Holanda \& Gauer, 2004). Fundamentalmente, destacam-se em sua obra, duas fases: a) uma preocupação com a "finalidade do mundo", e b) um interesse pelos "dados gerais da filosofia do espírito", expresso em dois de seus principais escritos, A Base Física do Espírito, de 1912 (Brito, 2006a); e O Mundo Interior, de 1914 (Brito, 2006b). Seu pensamento reserva grande espaço para a Psicologia, pretendendo que esta viesse a ser a base para a Filosofia.

Para Farias Brito, a realidade em si (objeto da metafísica) se resumiria à "vida interior" ou ao "espírito", sendo o mundo exterior (ou mecânico) entendido como pura aparência. Assim, a Psicologia devia ocupar-se dos fenômenos subjetivos da consciência, através do método introspectivo.

É neste caminho que consideramos Farias Brito como o precursor da fenomenologia e do existencialismo no Brasil, por sua tendência a recorrer às fontes subjetivas do conhecimento. Dito de outra forma, com Farias Brito, a filosofia se interioriza (Gomes, Holanda \& Gauer, 2004).

As idéias fenomenológicas no Brasil se fazem presentes, portanto, desde o princípio dos anos 1910 - com Farias Brito - mas só ganha destaque durante a década de 1940, a partir do que pode ser chamado de "ideário existencialista”, em duas vertentes: uma, de reflexão filosófica, e outra, de reflexão psicológica (Guimarães, 2000). Aliás, as preocupações de ordem psicológica, desde o século XIX, são dominantes no cenário da construção da ciência brasileira, associadas primordialmente à Medicina e à Educação, o que demonstra o fato de haver - desde essa época - um paralelismo entre o desenvolvimento das idéias filosóficas associadas ao pensamento médico e educacional (Antunes, 1998; Massimi, 2004). Desta feita, a história concreta do pensamento fenomenológico no Brasil está ligada a três nomes, fundamentalmente: Vicente Ferreira da Silva, Euryalo Cannabrava e Nilton Campos.

A primeira referência às idéias fenomenológicas no Brasil - exatamente por esta "via do ideário existencialis- ta” - é encontrada na figura de Vicente Ferreira da Silva, como um pioneiro na leitura de Heidegger (Morujão, 1990; Guimarães, 2000), dentro de uma perspectiva bastante influenciada pelo pensamento de Ortega y Gasset em nosso país.

Ainda na década de 40, do século passado, encontramos em Euryalo Cannabrava (1908-1978) outra referência ao pensamento heideggeriano, cujo pensamento passa por três fases. Na primeira, seu projeto era formular uma teoria filosófica baseada no contato direto com os problemas existenciais, e a busca por uma filosofia situada entre a fenomenologia husserliana e o existencialismo alemão (Abreu e Silva, 2001). Em 1941, Cannabrava publica um livro, intitulado Seis Temas do Mundo Moderno, onde o autor traça um panorama do pensamento existencial, baseando-se na ontologia heideggeriana (Guimarães, 2000; Abreu e Silva, 2001). Embora procure contestar os pressupostos do existencialismo, termina por se tornar um efetivo difusor do movimento fenomenológico no Brasil, a partir das leituras de Heidegger e de Jaspers.

A segunda fase de seu pensamento se caracteriza pelo livro Descartes e Bacon, de 1943 e por uma postura crítica. No pós-guerra, Cannabrava vai aos Estados Unidos, onde recebe a influência da Escola de Chicago. Posteriormente, em 1948, mantém contato com Alfred Whitehead, em Cambridge (Inglaterra), com o qual trava discussão sobre a estética dos países latino-americanos (Abreu e Silva, 2001).

Sua obra termina por ser fortemente influenciada pelo pensamento de Ludwig Wittgenstein, apontando para um "Sistema Logos-Psique", no qual defende um dualismo do espírito humano, existindo dois tipos de conhecimento: um, lógico ou epistêmico (baseado em operações abstratas) e o outro, psicológico ou cognitivo (fundamentado na observação empírica) (Abreu e Silva, 2001).

Mas as reflexões fenomenológicas relacionadas à investigação psicológica encontram suas primeiras manifestações através do trabalho de Nilton Campos, o que vem a ser decisivo para grande parte dos psicólogos e psiquiatras brasileiros (Morujão, 1990; Guimarães, 2000).

Nilton Campos (1898-1963), nascido no Rio de Janeiro, formou-se na Faculdade Nacional de Medicina da antiga Universidade do Brasil (atual Universidade Federal do Rio de Janeiro), voltando-se para a neurologia e a psiquiatria. Foi o primeiro profissional a dedica-se em tempo integral à Psicologia (Cabral, 1964).

Após sua especialização em psiquiatria, Nilton Campos passa a integrar, já em 1924, a equipe da Colônia de Psicopatas do Engenho de Dentro ${ }^{4}$, na época dirigida por Gustavo Riedel que, em 1923, cria um laboratório de Psicologia (Penna, 2001; Gomes, Holanda \& Gauer, 2004). Com o apoio financeiro da Fundação Graffée-Guinle,

\footnotetext{
4 Fundada em 1910. O Laboratório de Psicologia é posteriormente transformado em Instituto de Psicologia, subordinado - em 1932 - ao Ministério da Educação e Saúde Pública, e em 1937, é incorporado à antiga Universidade do Brasil.
} 
o laboratório foi instrumentalizado e passou à direção de Waclaw Radecki, do qual passa a ser assistente. O Laboratório funcionava como instituição auxiliar médica, como núcleo de pesquisas científicas e como centro didático de formação de psicólogos (Antunes, 1998).

Nilton Campos permanece no laboratório até 1930. Entre 1931 e 1933 - agora radicado em São Paulo - ajuda a organizar e fundar o Instituto Médico-Pedagógico Paulista - voltado para o trabalho com excepcionais -, com seu amigo Joaquim Penino (Penna, 2001). Ainda em São Paulo, Nilton Campos participa da fundação da Sociedade de Neuropsiquiatria de São Paulo.

A partir de 1934, já de volta ao Rio de Janeiro, torna-se diretor do Serviço Neuropsicológico da Secretaria de Saúde e Assistência a Psicopatas do Distrito Federal (Penna, 1992, 2001) e, no ano seguinte, é designado Diretor do Instituto de Psicologia de Assistência a Psicopatas, até 1937 (Penna, 1992, 2001; Gomes, Holanda \& Gauer, 2004). Teve ainda passagem como professor do Colégio Pedro II e na Faculdade Nacional de Filosofia (em substituição a Lourenço Filho).

A partir de 1944, passa a exercer a cátedra de Psicologia Geral, na Faculdade Nacional de Filosofia, em substituição a André Ombredane. Esta cátedra foi conquistada através de concurso, quando apresentou sua tese (Campos, 1945), preparada em 1945 e defendida em 1948, sob o título O Método Fenomenológico na Psicologia (Penna, 1992, 2001; Gomes, Holanda \& Gauer, 2004).

Numa sensível análise, Penna (1992) assinala, em $A$ História da Psicologia no Rio de Janeiro o esforço de Nilton Campos para encaminhar empiricamente o método fenomenológico. Um dos aspectos mais importantes do legado de Nilton Campos para a Fenomenologia e a Psicologia brasileiras é o fato que este antecipa, já em sua tese, a potencialidade desse método para a pesquisa psicológica, além da proximidade com vários aspectos da Psicologia da Gestalt, destacando, contudo, uma percepção crítica da apropriação desta escola do método fenomenológico, quando aponta para a necessidade de modificação do método para melhor adequação à pesquisa em Psicologia (Gomes, Holanda \& Gauer, 2004).

O texto de Nilton Campos permanece, ainda hoje, como um texto atual e singular, pela sua clareza de exposições e, principalmente, por sua visão crítica e aberta do método. Como assinala em sua tese, a "pesquisa fenomenológica procura descobrir, e não, inventar" (Campos, 1945, p. 17). Defendendo uma posição compreensiva da pesquisa em psicologia - na mesma direção da proposição diltheyana - completa: “...a investigação fenomenológica tem que se afastar tanto da interpretação vulgar como da reflexão lógica sobre a natureza da realidade" (Campos, 1945, p. 44).

Com esta breve digressão, pretendemos apontar que a Fenomenologia no Brasil chega tardiamente - embora devidamente antecipada - e associada ao pensamento heideggeriano, que guarda significativas distinções com o pensamento husserliano, o que contribui certamente para a inapropriação deste pensamento em nosso meio intelectual até o momento.

Em outras palavras, o conhecimento fenomenológico puro só vem a ser conhecido do grande público por um viés de identidade com pensadores posteriores a Husserl - como Heidegger, por exemplo - e sem um aprofundamento nas obras capitais da disciplina. Como reforço a esta tese, basta-nos apontar, por fim, para o fato que ainda hoje temos poucas traduções das obras husserlianas para nosso idioma.

\section{Quarto e Último Ponto ou Considerações Finais}

Há que considerarmos, finalmente, que é uma profunda admiração pelo árduo e contínuo esforço de Husserl em prol da clarificação da experiência humana, que faz dele sim, um psicólogo. E com isto não estamos apenas nos apropriando do "primeiro Husserl”, como destacado por alguns autores, referindo-se à sua fase "psicologista” (Lantéri-Laura, 1963; Mohanty, 1996; Smith \& Smith, 1996) ou, como assinala Marvin Farber, à sua “fase pré-fenomenológica” (Penna, 1986). Esta, segundo a maioria dos intérpretes, refere-se aos primeiros estudos de Husserl na direção da reflexão matemática e da fundamentação lógica, o que o aproxima da Psicologia nascente da época.

Referimo-nos - ao contrário - a Husserl como estudioso dos processos de consciência, o que justifica sua colocação como psicólogo, dado que entendemos a Psicologia como a ciência da consciência e dos processos que envolvem essa consciência, seja a mesma entendida tanto a partir das teorias que propõem uma interioridade, seja em suas múltiplas relações com o mundo, abarcando a totalidade da existência humana em suas dimensões sociais, culturais, etc.

Com isto, e com esta apresentação, esperamos ter apontado para as intrínsecas e necessárias aproximações - ou "diálogos e interlocuções" - entre a Fenomenologia e a Psicologia.

Como derradeiro ponto, acrescentamos tão somente o conceito de "horizonte", que encontramos na obra de Husserl - ao lado da noção de Lebenswelt - como uma das noções que mais influencia os pensadores posteriores a ele, como Heidegger, Merleau-Ponty, Gadamer, Habermas, Apel e Ricouer (Zilles, 1996), e que se refere à possibilidade da realidade sem limites, mas próxima ao sujeito, vivida, “à mão”. Nas palavras de Valentini (1997):

O horizonte se dá no interior e no exterior da experiência. (...) É na dimensão do horizonte que se descobrem os significados ideais e infinitos; a consciência transcendental evidencia o plano de uma constituição de racionalidade, que é essencialmente possibilidade e liberdade (p. 51-52). 
Em outras palavras, é no horizonte que se descortinam as possibilidades de existência do ser, que se dão fundamentalmente na intencionalidade e na intersubjetividade. Talvez possamos compreender melhor esse conceito de uma maneira metafórica, através de uma pequena história:

Certa vez alguém chegou ao céu e pediu para falar com Deus. Segundo o seu ponto de vista, havia uma coisa na criação que não tinha nenhum sentido. Deus atendeu de imediato, curioso por saber qual era a falha que havia na criação.

- Senhor, sua criação é muito bonita, muito funcional, cada coisa tem sua razão de ser, mas, no meu ponto de vista, tem uma coisa que não serve para nada.

- E que coisa é essa que não serve para nada? - perguntou Deus.

- É o horizonte. Para que serve o horizonte? Se eu caminho um passo em sua direção, ele se afasta um passo de mim. Se caminho dez passos, ele se afasta outros dez passos. Isto não faz sentido! O horizonte não serve pra nada.

Deus sorriu e disse:

- Mas é justamente para isso que serve o horizonte... para fazê-lo caminhar e nunca desistir de lutar pelo amanhã.

\section{Referências}

Abreu e Silva Neto, N. (2001). Euryalo Cannabrava. Em Regina H. F. Campos (Org.), Dicionário Biográfico da Psicologia no Brasil (p. 114-119). Rio de Janeiro: Imago / Brasília: Conselho Federal de Psicologia.

Antunes, M. A. M. (1998). A Psicologia no Brasil. Leitura histórica sobre sua constituição. São Paulo: Unimarco/Educ.

Brito, F. (2006a). A Base Física do Espírito. Brasília: Senado Federal.

Brito, F. (2006b). O Mundo Interior: ensaio sobre os dados gerais da filosofia do espírito. Brasília: Senado Federal.

Cabral, A. (1964). Nilton Campos (1898-1963). Jornal Brasileiro de Psicologia, 1(2), 3-12.

Campos, N. (1945). O Método Fenomenológico na Psicologia, Rio de Janeiro, Tese para Concurso de Cátedra da Universidade do Brasil.

Gomes, W. B., Holanda, A. F., \& Gauer, G. (2004). História das Abordagens Humanistas em Psicologia no Brasil. Em Marina Massimi (Org.), História da Psicologia no Brasil do Século XX (p. 105-130). São Paulo: E.P.U.

Guimarães, A.C. (2000). O Pensamento Fenomenológico no Brasil. Revista Brasileira de Filosofia, 50, 198, p. 258-267.

Husserl, E. (1985). Idées Directrices pour une Phénoménologie et une Philosophie Phénoménologique Pures. Paris: Gallimard.
Husserl, E. (1992). Conferências de Paris. Lisboa: Edições 70.

Lantéri-Laura, G. (1963). La Psychiatrie Phénoménologique. Fondements philosophiques. Paris: Presses Universitaires de France.

Lévinas, E. (1989). Théorie de l’Intuition dans la Phénoménologie de Husserl. Paris: Librairie Philosophique J.Vrin.

Maciel, J. C. (2003). Fraz Clemens Brentano e a Psicologia. Em Maria Alves de Toledo Bruns \& Adriano Furtado Holanda (Orgs.), Psicologia e Fenomenologia. Reflexões e Perspectivas (p. 27-40). Campinas: Alínea.

Massimi, M. (Org.) (2004). História da Psicologia no Brasil do Século XX. São Paulo: E.P.U.

Merleau-Ponty, M. (1945). Phénoménologie de la Perception. Paris: Gallimard.

Mohanty, J. N. (1996). The Development of Husserl's Thought. Em Barry Smith \& David W. Smith, The Cambridge Companion to Husserl (p. 45-77). Cambridge: Cambridge University Press.

Morujão, A. F. (1990). O Movimento Fenomenológico. Em Logos. Enciclopédia Luso-Brasileira de Filosofia. Lisboa: Verbo.

Normando, R. N. (1985). Física Fenomenológica. Fortaleza: Edições UFC.

Penna, A. G. (1986). Dicionário de Ciências Sociais. Rio de Janeiro: Editora da Fundação Getúlio Vargas.

Penna, A. G. (1992). História da Psicologia no Rio de Janeiro. Rio de Janeiro: Imago.

Penna, A. G. (2001). Nilton Campos. Em Regina H. F. Campos (Org.), Dicionário Biográfico da Psicologia no Brasil (p. 112114). Rio de Janeiro: Imago / Brasília: Conselho Federal de Psicologia.

Smith, B., \& Smith, D. W. (Eds.) (1996). The Cambridge Companion of Husserl. Cambridge: Cambridge University Press.

Valentini, L. (1997). Idéia de horizonte e mundo na fenomenologia Husserliana. Estudos de Psicologia (Campinas), 14(3), 49-56.

Zilles, U. (1996). Introdução. Em Edmund Husserl, A Crise da Humanidade Européia e a Filosofia. Porto Alegre: Edipucrs.

Adriano Holanda - Doutor em Psicologia e Professor Adjunto da Universidade Federal do Paraná. Endereço para correspondência: Departamento de Psicologia, Universidade Federal do Paraná, Praça Santos Andrade, 50 - Sala 215 (Ala Alfredo Buffren). CEP: 80060.240 - Curitiba / PR. Email: aholanda@yahoo.com

Recebido em 23.07.09 Aceito em 06.08.09 